\title{
Renal Adaptation to a High Potassium Intake
}

\author{
THE ROLE OF HYDROGEN ION
}

\author{
Richard L. Tannen, Eric Wedell, and Ronda Moore \\ From the Department of Medicine, University of Vermont College of Medicine, \\ Burlington, Vermont 05401
}

\begin{abstract}
A в S T R A C T The influence on urinary acidification of prolonged ingestion of a high potassium diet was explored in normal men and dogs. In men, the response to acute ingestion of ammonium chloride was assessed in a paired fashion after 5 days of ingesting a formula diet of normal or high potassium content; whereas in animals chronically ingesting a small amount of hydrochloric acid, the response to an increase in daily potassium intake was assessed. Urine $\mathrm{pH}$ was lower in the potassium-loaded state with both these models, and the effect persisted in the dog studies as long as a high potassium intake was continued. The decrease in urine $\mathrm{pH}$ could not be accounted for by changes in plasma acid-base status, net acid excretion, rate of urine flow, urine ionic strength, or fixed buffer excretion, i.e., phosphate, creatinine, or organic acids. Studies of men with administration of exogenous aldosterone and studies of adrenalectomized dogs with constant, maintenance steroid replacement indicated that the decrease in urine $\mathrm{pH}$ does not result from altered aldosterone secretion.

In the human studies the largest decreases in urine $\mathrm{pH}$ were associated with a concomitant diminution in both ammonium and net acid excretion, suggesting a primary decrease of ammonia diffusion into the urine. These events during potassium loading, which are the mirror image of changes during potassium depletion, suggest that the relation between potassium, urine acidification, and ammonia metabolism may play an important role in the maintenance of hydrogen ion and possibly potassium homeostasis during alterations in potassium intake.
\end{abstract}

Preliminary reports appeared in the Abstracts of the American Society of Nephrology, 1971. 5: 80. and Clin. Res. 1972. 20: 612, 613.

Dr. Tannen is an Established Investigator of The American Heart Association.

Received for publication 13 June 1972 and in revised form 12 February 1973.

\section{INTRODUCTION}

The acute administration of a potassium load results in an alkaline diuresis, presumably the result of an interaction between renal handling of potassium and hydrogen ion. It has been speculated that these ions are secreted in a competitive fashion (1) and that the mechanism involves a decrease in renal tubular cellhydrogen ion content $(2,3)$.

On the other hand, urinary acidification after the chronic ingestion of a high potassium intake has received little attention. This seemed particularly cogent in light of recent studies of urinary acidification during potassium depletion that suggested an interaction between potassium regulation and renal ammonia production (4). The possibility that this mechanism might also play a role in the adaptive response to potassium loading was of interest, especially since the process leading to enhanced renal potassium excretion during chronic ingestion of a high potassium intake is currently undefined $(3,5-7)$.

Therefore, urinary acidification was explored during chronic potassium loading in normal men and dogs. In contrast to acute administration, chronic potassium loading resulted in a decrease in urine $\mathrm{pH}$ when tested under acidifying conditions. This change was persistent during prolonged potassium loading, and was not the result of changes in plasma acid-base status, urinary net acid excretion, or alterations in aldosterone secretion. Furthermore it appeared to be accompanied by a primary diminution in ammonia diffusion into the urine. The potential role of these alterations in urinary acidification in the adaptive response to potassium ingestion is considered.

\section{METHODS}

\section{Human studies}

15 normal informed male volunteers were subjects for three experimental protocols. All protocols consisted of a 
control and an experimental study with at least 7 days on a normal diet between studies. A low electrolyte food powder $^{1}$ described previously (4), supplemented with magnesium, sodium, and potassium chloride, was ingested preceding both phases of all protocols. It provided daily: 35 cal, $30 \mathrm{ml}$ of water, $0.1 \mathrm{mmol}$ of magnesium, $2 \mathrm{mmol}$ of sodium, and $0.75 \mathrm{mmol}$ of potassium per $\mathrm{kg}$ of body weight. During the high potassium phases of the protocols, from 3.0 to $6.0 \mathrm{mmol} / \mathrm{kg}$ of potassium and an additional $15 \mathrm{ml} / \mathrm{kg}$ of water were given.

Protocol 1: high potassium (eight studies). An acute $\mathrm{NH}_{4} \mathrm{Cl}$ study was performed as described below after 5 days of formula diet with normal electrolyte content and on a second occasion after 5 days of formula diet with a high potassium content.

Protocol 2: high potassium-glutamine (five studies). As in protocol 1, 5 days of formula diet with normal or high potassium content $(5.0 \mathrm{mmol} / \mathrm{kg}$ per day $)$ preceded the acute studies. The acute studies differed from the acute $\mathrm{NH}_{4} \mathrm{Cl}$ study described below as follows: in addition to $\mathrm{NH}_{4} \mathrm{Cl}, 5 \mathrm{mmol} / \mathrm{kg}$ of $l$-glutamine in $1,000 \mathrm{ml}$ of water was ingested between 11:00 a.m. and 12:00 noon.

Protocol 3: aldosterone (three studies). Acute $\mathrm{NH}_{4} \mathrm{Cl}$ studies were performed on two occasions after 3 days of formula diet with normal electrolyte content. On the day of the second $\mathrm{NH}_{4} \mathrm{Cl}$ study, $200 \mu \mathrm{g}$ of $d$-aldosterone acetate in sesame oil was given intramuscularly at 6:00 a.m., 10:00 a.m., and 2:00 p.m.

Ammonium chloride procedure. All the ammonium chloride studies were performed under controlled conditions described previously (4). In brief, after two hourly urine collections, ammonium chloride in gelatin capsules (2 $\mathrm{mmol} / \mathrm{kg}$ of body weight) was taken from 9:00 to 11:00 a.m. and six subsequent hourly urines were collected. Venous blood was collected without stasis before ingestion of ammonium chloride and 2 and $5 \mathrm{~h}$ thereafter.

\section{Animal studies}

Multiple chronic studies were performed in six female mongrel dogs weighing $16.3-26.1 \mathrm{~kg}$. The animals were housed in metabolic cages with siliconized collection pans, and daily urine collections were made into containers with thymol and mineral oil. Heparinized arterial blood samples were drawn in the morning in the fasting state. The dogs were fed daily in two approximately equal portions $25 \mathrm{~g} / \mathrm{kg}$ of a low electrolyte formula diet whose composition has been described previously (8). The diet was homogenized with two times its weight of water and supplemented with $\mathrm{NaCl}$ and $\mathrm{KCl}$. Animals that did not eat spontaneously were tube fed.

Three basic protocols were employed with each generally consisting of control, potassium-loading, and recovery periods. In some instances a sodium loading and/or a second potassium-loading period was also performed. Control periods lasted 5-8 days and other periods were generally 6-8 days long.

Protocol 1: high potassium (three dogs). During the control and recovery periods, the diet was supplemented with $4 \mathrm{mmol} / \mathrm{kg}$ per day of $\mathrm{NaCl}$ and $0.75 \mathrm{mmol} / \mathrm{kg}$ per day of $\mathrm{KCl}(1 \mathrm{mmol} / \mathrm{kg}$ per day in dog 1$)$. During the potassium-loading periods, $\mathrm{KCl}$ was increased to either 5 or $10 \mathrm{mmol} / \mathrm{kg}$ per day.

Protocol 2: high potassium- $\mathrm{HCl}$ (six dogs). Animals were maintained on $2 \mathrm{mmol} / \mathrm{kg}$ per day of $\mathrm{HCl}$ at least 7

\footnotetext{
${ }^{1}$ Mead Johnson Labs., Evansville, Ind., Product $7000 \mathrm{~J}$.
}

days before collections were begun and throughout the entire study. Control, potassium loading, and recovery periods were otherwise identical with the high potassium protocol. During sodium-loading periods $\mathrm{NaCl}$ intake was increased either 4.25 or $9.25 \mathrm{mmol} / \mathrm{kg}$ per day above baseline intake, so that $\mathrm{Cl}^{-}$intake was equivalent to the comparable potassium-loading period. In $\operatorname{dog} 1, \mathrm{NaCl}$ was inadvertently increased by only $4.5 \mathrm{mmol} / \mathrm{kg}$ per day compared with a potassium-loading period of $10 \mathrm{mmol} / \mathrm{kg}$ per day.

Protocol 3: adrenalectomy (three dogs). Dogs underwent total adrenalectomy at least 1 mo before study. They were maintained throughout the protocol on $8 \mathrm{mg} / \mathrm{day}$ of oral hydrocortisone and $0.5 \mathrm{mg} /$ day of deoxycorticosterone acetate in oil given intramuscularly. Experimental periods were otherwise similar to the "high potassium- $\mathrm{HCl}$ protocol" however the first potassium-loading period was uniformly with $5 \mathrm{mmol} / \mathrm{kg}$ per day of $\mathrm{KCl}$. A second potassium-loading period with $10 \mathrm{mmol} / \mathrm{kg}$ per day was attempted in all dogs.

Chemical determinations. Blood and urine $\mathrm{pH}$ were determined anaerobically at $37^{\circ} \mathrm{C}$ with a Corning model 12 blood $\mathrm{pH}$ system (Corning Glass Works, Science Products Div., Corning, N. Y.). Plasma and urine total $\mathrm{CO}_{2}$ was determined manometrically with a Natelson microgasometer. Chloride was measured with an Aminco Cotlove chloride titrator (American Instrument Co., Inc., Silver Springs, Md.). Sodium and potassium were measured by flame photometry with an internal lithium standard using an Instrumentation Laboratory flame photometer (Instrumentation Laboratory, Inc., Lexington, Mass.). Phosphate (9), ammonium (10), and creatinine (11) were determined spectrophotometrically. Dephosphated urine specimens were titrated from $\mathrm{pH} 2.7$ to 8.0 to determine total organic acids (12), and from urine $\mathrm{pH}$ to 7.40 to determine nonphosphate-titratable acid.

Calculations. Bicarbonate concentration and $\mathrm{P}_{\mathrm{CO}_{2}}$ were calculated from the Henderson-Hasselbalch equation, assuming a $\mathrm{pK}_{\mathrm{a}}{ }^{\prime}$ of 6.10 , and a solubility coefficient of 0.0301 for blood and 0.0309 for urine. In the human studies, titratable acidity was calculated as the sum of the measured nonphosphate-titratable acid and the phosphate contribution calculated from urine $\mathrm{pH}$, blood $\mathrm{pH}$, and urinary phosphate content with $\mathrm{pK}_{a}^{\prime}$ of 6.8 ; however, in the animal studies only the phosphate contribution was utilized. Net acid excretion was calculated as ammonium plus titratable acidity minus bicarbonate. Urine-free ammonia was calculated from the equation $\mathrm{NH}_{3}=$ total ammonia/antilog $\left(\mathrm{pK}_{a}^{\prime}\right.$ $\mathrm{pH}$ ) with a $\mathrm{pK}_{a}^{\prime}$ of 9.0 . The data were all analyzed statistically in a paired fashion utilizing a " $t$ " test.

\section{RESULTS}

\section{Human studies}

\section{High Potassium and High Potassium-Glutamine} Protocols

Acid base. Mean plasma acid-base values on the day of the ammonium chloride study are given in Table I. Values for the high potassium and high potassiumglutamine protocc's were combined since the plasma acid-base response as similar in both. No differences in plasma bicarbonatc concentration, $\mathrm{pH}$, or $\mathrm{Pco}_{2}$ were noted between normal and high potassium studies before or after ingestion of ammonium chloride. 
TABLE I

Mean Plasma Values

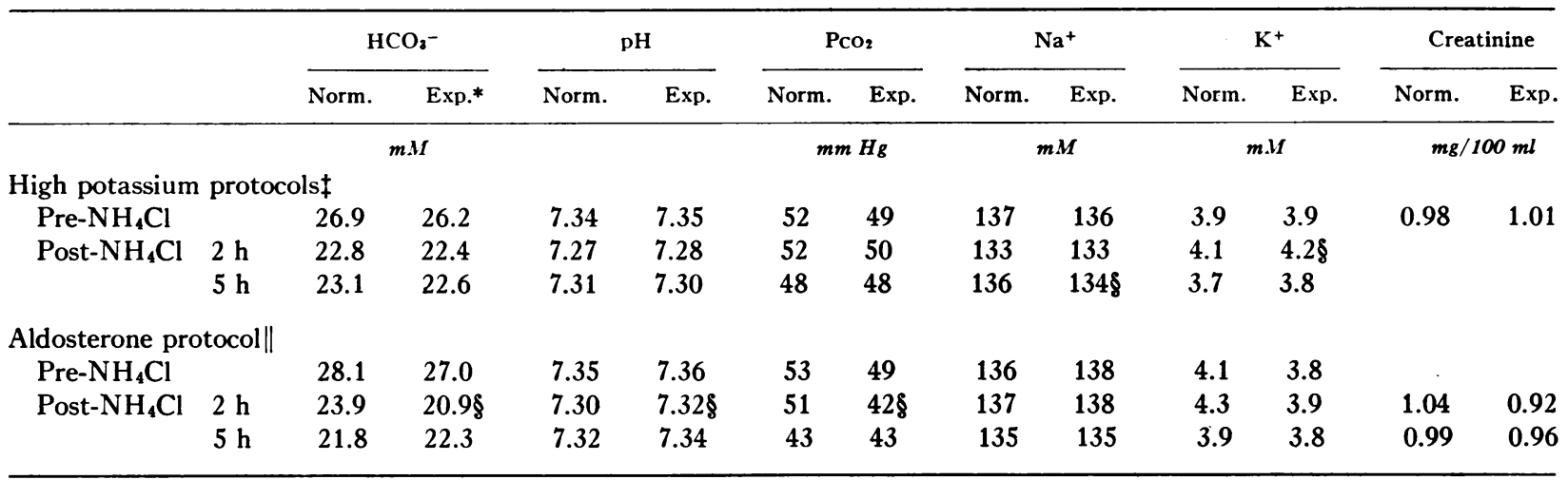

* Norm. refers to normal studies, Exp. to experimental studies.

$\ddagger$ Includes both high potassium and high potassium-glutamine protocols; $n=13$ for acid-base parameters and $n=7$ for electrolyte values.

$\S$ Indicates a significant difference between experimental and normal studies, $P<0.05$.

$\| n=3$ for all observations.

The $\mathrm{pH}$ of the control urine collections before the ingestion of ammonium chloride averaged 5.38 with the high potassium diet compared with 5.57 with a normal intake. This change is significant statistically when mean hydrogen ion concentration is compared $(P<0.05)$, but not if mean $\mathrm{pH}$ values are compared. In these control collections, urine flow rate was higher during high potassium intake, 3.2 vs. $1.7 \mathrm{ml} / \mathrm{min}$, and no significant differences were found in net acid (50.1 vs. $46.1 \mu \mathrm{mol} / \mathrm{min}$ ), ammonium ( 42.7 vs. $39.2 \mu \mathrm{mol} /$ $\mathrm{min})$, phosphate $(8.7$ vs. $7.9 \mu \mathrm{mol} / \mathrm{min})$, or creatinine (9.4 vs. $9.2 \mu \mathrm{mol} / \mathrm{min}$ ) excretion.

Mean urinary acid-base values after ingestion of $\mathrm{NH}_{4} \mathrm{Cl}$ for the paired normal and high potassium studies are given in Table II. In addition, each hourly value obtained during a subject's high potassium study was compared with the value obtained during the same time period of his normal study and these comparisons are plotted in the figures.

After the ingestion of $\mathrm{NH}_{4} \mathrm{Cl}$, urine $\mathrm{pH}$ was significantly lower during studies with a high potassium diet averaging 4.65 compared with 4.86 (Fig. 1 and Table II). Furthermore, there was no apparent difference in the response at $3.0,4.5$, and $6.0 \mathrm{mmol} / \mathrm{kg}$ per day of potassium intake. For this reason data from all high potassium studies were pooled for analysis.

Significant differences between the normal and high potassium studies were not found for net acid, ammonium, phosphate, or creatinine excretion or for urine flow rate (Table II). Organic acid excretion was significantly lower in the high potassium studies, 15.5 vs. $17.9 \mu \mathrm{mol} / \mathrm{min}$; however, nonphosphate-titratable acid excretion was increased significantly, 5.4 compared with $4.9 \mu \mathrm{mol} / \mathrm{min}$. If a decrease in buffer excretion alone is responsible for a decrease in $\mathrm{pH}$, the quantity of that buffer combined with hydrogen ion will remain unaltered or decrease. Therefore the increase in nonphosphate-titratable acid indicates that some factor other than a decrease in organic acid excretion must be contributing to the decrease in urine $\mathrm{pH}$. Urine-free ammonia concentration was significantly lower in the high potassium studies, 1.6 vs. $2.1 \mu \mathrm{M}$, but no differences in urine $\mathrm{Pco}_{2}$ were apparent.

Since the variables responsible for the decrease in urine $\mathrm{pH}$ should be most evident when the changes in urine $\mathrm{pH}$ are largest, the data were analyzed by relating the change in urine $\mathrm{pH}$ for each collection period to the

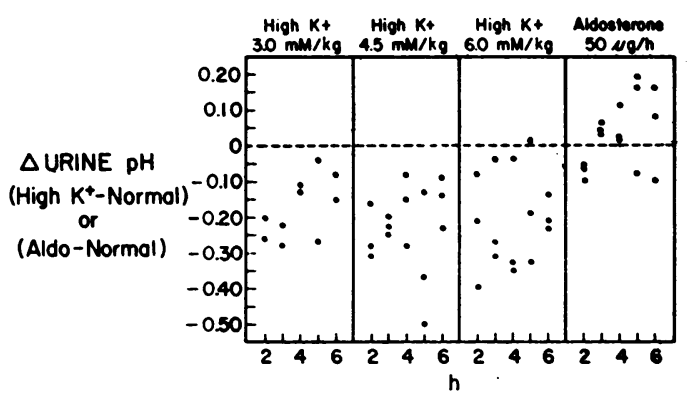

FIgUre 1 The effect of a high potassium intake and aldosterone on urine $\mathrm{pH}$. Each point in this and all subsequent figures represents a comparison between the response during a comparable time period of a paired experimental and control study. Only the periods from 2 to $6 \mathrm{~h}$ after the ingestion of $\mathrm{NH}_{4} \mathrm{Cl}$ are plotted. Urine $\mathrm{pH}$ is significantly diminished by a high potassium intake and unaffected by aldosterone. 
TABLE II

Mean Urinary

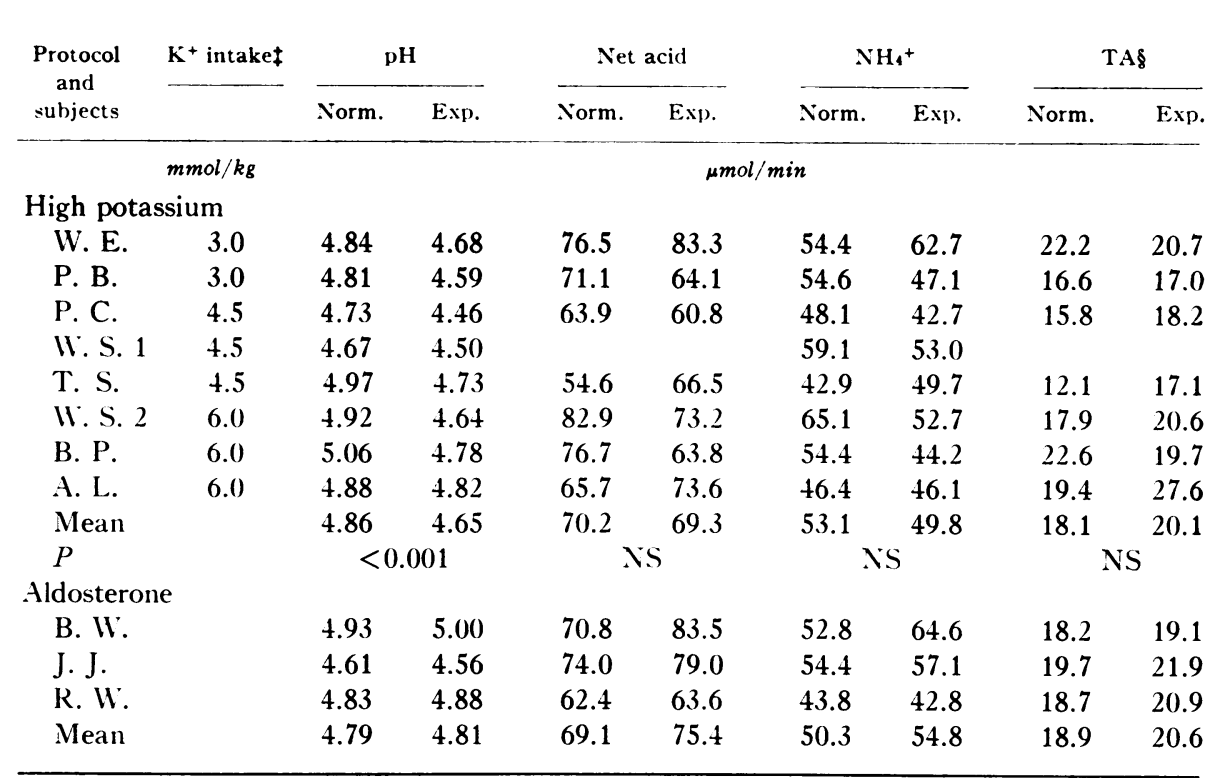

* Mean values from the $2 \mathrm{nd}$ to 6 th $\mathrm{h}$ after ingestion of $\mathrm{NH}_{4} \mathrm{Cl}$.

$\ddagger$ Potassium intake during high potassium study.

$\S \mathrm{TA}=$ titratable acid.

$\| P$ value refers to comparison between normal and experimental studies.

change in other pertinent variables. As shown in Fig. 2, when urine $\mathrm{pH}$ decreased by more than $0.20 \mathrm{U}$, it appeared to be associated with a concomitant decrease in both ammonium and net acid excretion. If the one point, which appears to be aberrant, plotted as an open circle in Fig. 2, is eliminated, the decrease in net acid averaged $7.5 \mu \mathrm{mol} / \mathrm{min}$ and in ammonium $7.9 \mu \mathrm{mol} / \mathrm{min}$ for those periods with a $\mathrm{pH}$ change greater than 0.20 . These differences are statistically significant at the $1 \%$ level using a paired $t$ test.

If possible it would be preferable to demonstrate more dramatic changes in ammonium and net acid excretion. Since changes in urine $\mathrm{pH}$ were similar at potassium intakes of 3.0 and $6.0 \mathrm{mmol} / \mathrm{kg}$ suggesting a near maximal effect had been achieved, studies at higher intakes with their potential risks did not appear warranted. Another alternative was to amplify base-line rates of ammonium and net acid excretion, with the possibility that differences might also be amplified. Therefore studies with simultaneous glutamine and ammonium chloride were performed; however, no differences in either ammonium (111 vs. $110 \mu \mathrm{mol} / \mathrm{min}$ ) or net acid (127 vs. $129 \mu \mathrm{mol} / \mathrm{min}$ ) excretion were found between the normal and high potassium studies. Furthermore, erratic urine flow rates and variability in peak glutamine effect tended to obscure changes in urine $\mathrm{pH}$. It was lower in four of five high potassium studies and averaged 5.26 compared with 5.39 ; however, this difference was not statistically significant.

Electrolytes. Ingestion of a high potassium diet resulted in a natriuresis, averaging $201 \mathrm{mmol}$, that had subsided by the end of the second day. It was accom. panied by negative chloride balance, a reduction in weight, and greater urinary water loss in comparison with the normal studies. Subsequently the data suggest modest sodium and chloride retention and by the morning of the 6th day the weights were virtually identical with the high and normal potassium diets. Concomitant with the natriuresis, a significant amount of potassium was retained during the initial 2 days of high potassium intake but by the last 2 days urinary potassium excretion averaged $95 \%$ of intake. Without making any estimate for stool potassium loss, potassium retention averaged $219 \mathrm{mmol}$.

Plasma electrolyte values on the day of $\mathrm{NH} \cdot \mathrm{Cl}$ ingestion are given in Table I and urinary electrolyte data after the ingestion of $\mathrm{NH}_{4} \mathrm{Cl}$ are given in Fig. 3. Sodium excretion was lower (72 vs. $146 \mu \mathrm{mol} / \mathrm{min}$ ) whereas potassium excretion was higher (156 vs. 84 $\mu \mathrm{mol} / \mathrm{min})$ in the high potassium studies. No significant differences in $\mathrm{Cl}^{-}$excretion were found (235 vs. 265 $\mu \mathrm{mol} / \mathrm{min})$ and calculated $\left(\mathrm{Cl}^{-}-\mathrm{Na}^{+}\right)$excretion was significantly higher (163 vs. $119 \mu \mathrm{mol} / \mathrm{min})$ in the high potassium studies. 


\begin{tabular}{|c|c|c|c|c|c|c|c|c|c|}
\hline \multicolumn{2}{|c|}{$\begin{array}{c}\text { Nonphosphate } \\
\text { TA }\end{array}$} & \multicolumn{2}{|c|}{ Phosphate } & \multicolumn{2}{|c|}{ Creatinine } & \multicolumn{2}{|c|}{ Organic acid } & \multicolumn{2}{|c|}{ Volume } \\
\hline Norm. & Exp. & Norm. & Exp. & Norm. & Exp. & Norm. & Exp. & Norm. & Exp. \\
\hline \multicolumn{8}{|c|}{$\mu \mathrm{mol} / \mathrm{min}$} & \multicolumn{2}{|c|}{$m l / m i n$} \\
\hline 5.4 & 5.6 & 21.4 & 19.1 & 9.9 & 10.2 & 21.4 & 19.1 & 2.6 & 2.3 \\
\hline 5.1 & 5.3 & 15.4 & 14.4 & 7.2 & 9.6 & 15.1 & 16.0 & 2.2 & 3.2 \\
\hline \multirow[t]{2}{*}{4.8} & 5.9 & 15.0 & 15.5 & 9.2 & 8.6 & 15.9 & 12.3 & 1.7 & 2.6 \\
\hline & & & & 10.3 & 10.8 & & & 2.5 & 2.7 \\
\hline 4.0 & 4.1 & 10.3 & 16.7 & 6.8 & 6.8 & 11.9 & 8.4 & 2.4 & 3.2 \\
\hline 5.8 & 6.2 & 15.3 & 18.2 & 10.4 & 8.8 & 24.1 & 18.8 & 1.1 & 1.6 \\
\hline 4.5 & 5.4 & 23.3 & 18.1 & 10.7 & 9.3 & 17.7 & 17.1 & 2.3 & 1.7 \\
\hline 5.0 & 5.0 & 18.3 & 28.7 & 10.3 & 10.2 & 19.0 & 16.8 & 1.8 & 2.0 \\
\hline 4.9 & 5.4 & 17.0 & 18.7 & 9.3 & 9.3 & 17.9 & 15.5 & 2.1 & 2.4 \\
\hline \multicolumn{2}{|c|}{$<0.05$} & \multicolumn{2}{|c|}{ NS } & \multicolumn{2}{|c|}{ NS } & \multicolumn{2}{|c|}{$<0.025$} & \multicolumn{2}{|c|}{ NS } \\
\hline 4.6 & 4.4 & 17.2 & 18.7 & 10.0 & 9.6 & 17.5 & 16.9 & 1.8 & 1.8 \\
\hline 5.9 & 6.6 & 17.4 & 19.5 & 8.3 & 9.4 & 16.6 & 19.4 & 2.1 & 1.3 \\
\hline 4.5 & 5.1 & 18.0 & 20.1 & 8.5 & 9.0 & 17.0 & 20.4 & 1.9 & 1.7 \\
\hline 5.0 & 5.4 & 17.5 & 19.4 & 8.9 & 9.3 & 17.0 & 18.9 & 1.9 & 1.6 \\
\hline
\end{tabular}

\section{Aldosterone Protocol}

Because of the possibility that an increase in aldosterone secretion might be responsible for the change in urinary acidification and electrolyte excretion, the response to ingestion of $\mathrm{NH}_{4} \mathrm{Cl}$ was tested during administration of exogenous aldosterone in quantities approximating secretion rates during ingestion of a high potassium diet $(13,14)$.

Electrolyte. Plasma electrolyte values for the aldosterone studies are given in Table I and urinary electrolyte values after the ingestion of $\mathrm{NH}_{4} \mathrm{Cl}$ are given in Fig. 3. Sodium excretion diminished with aldosterone administration from 158 to $83 \mu \mathrm{mol} / \mathrm{min}$, which approximates the changes seen in the high potassium studies, whereas the increase in potassium excretion from 71 to $91 \mu \mathrm{mol} / \mathrm{min}$ was less marked. Chloride excretion was diminished from 252 to $195 \mu \mathrm{mol} / \mathrm{min}$; and consistent effects were not found in calculated $\left(\mathrm{Cl}^{-}-\mathrm{Na}^{+}\right)$ excretion.

Acid base. Plasma acid-base values are given in Table $I$ and urinary acid-base values are given in Table II and Fig. 1. Aldosterone did not result in any detectable changes in urine $\mathrm{pH}$; although there appeared to be a slight increase in net acid excretion.

\section{Animal studies}

\section{Acid BAse}

The plasma data reflect mean values obtained after the first 3 days of a given period, by which time an apparent steady state had been established; while the urinary data shown in Table III are the mean values for an entire period. Analyzing the urinary data by separately considering the changes in the first 3 days and the remainder of each period did not lead to different conclusions. If a daily urine collection was lost the data were utilized so long as sufficient collections were obtained to ensure an accurate mean excretion rate for the period; however, only studies in which all potassium loading and recovery collections were complete were used for cumulative net acid excretion calculations. The points in the figures were derived by calculating a mean control value for the parameter and plotting the difference between each determination and this value.

High potassium protocol. An increase in daily potassium intake to either 5 or $10 \mathrm{mmol} / \mathrm{kg}$ did not result in any changes in plasma bicarbonate concentration, $\mathrm{pH}$, or $\mathrm{Pcos}_{2}$. Urine $\mathrm{pH}$, net acid, ammonium and phosphate excretion were also unchanged in response to 


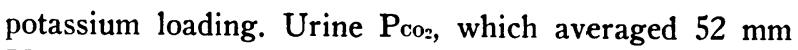
$\mathrm{Hg}$ during control, increased strikingly to $93 \mathrm{~mm} \mathrm{Hg}$ during potassium loading, and returned to base-line values during the recovery period.

$\mathrm{High}$ potassium- $\mathrm{HCl}$ protocol. A small increase in plasma $\mathrm{HCO}_{3}$ concentration from 17.7 to $19.1 \mathrm{mM}$ accompanied ingestion of a high potassium diet with return to control levels during the recovery period. It was not accompanied by significant changes in either plasma $\mathrm{pH}$ or $\mathrm{Pco}_{2}$ although mean $\mathrm{pH}$ was slightly higher during potassium loading; and there were no clear-cut changes in plasma acid-base parameters during ingestion of a high $\mathrm{NaCl}$ intake.

In contrast to the urinary findings in the first protocol, animals ingesting a small daily dose of $\mathrm{HCl}$ responded in a strikingly different fashion to an increase in daily potassium intake. Urine $\mathrm{P}_{\mathrm{co}_{2}}$ remained unchanged. On the other hand, as shown in Fig. 4 and Table III, ingestion of a high potassium intake resulted in a significant and persistent decrease in urine $\mathrm{pH}$ from a mean of 5.80 to 5.46 with return to base-line values during the recovery period. Furthermore the ingestion of comparable quantities of sodium chloride did not result in any alteration of urine $\mathrm{pH}$.

As shown in Fig. 5, the decrease in urine $\mathrm{pH}$ during $\mathrm{KCl}$ loading was accompanied by an increase in net acid excretion from 71.0 to $80.4 \mathrm{mmol} / \mathrm{day}$, that in large measure resulted from an increase in ammonium excretion. During the recovery period mean net acid

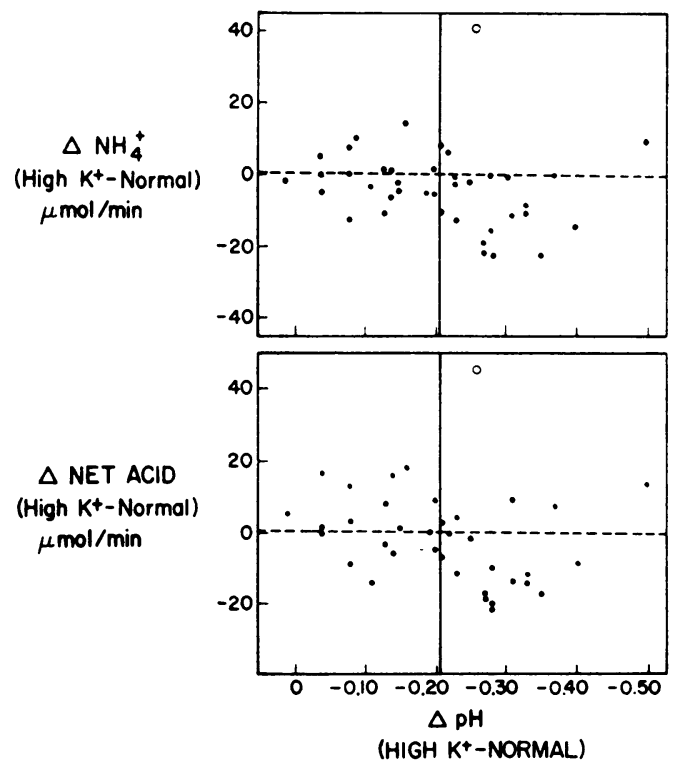

Figure 2 The relation of urine $\mathrm{pH}$ to ammonium and net acid excretion. One aberrant point depicted as an open circle is excluded from statistical analysis. A decrease in urine $\mathrm{pH}$ greater than 0.20 is accompanied by a significant decrease in both ammonium and net acid excretion.
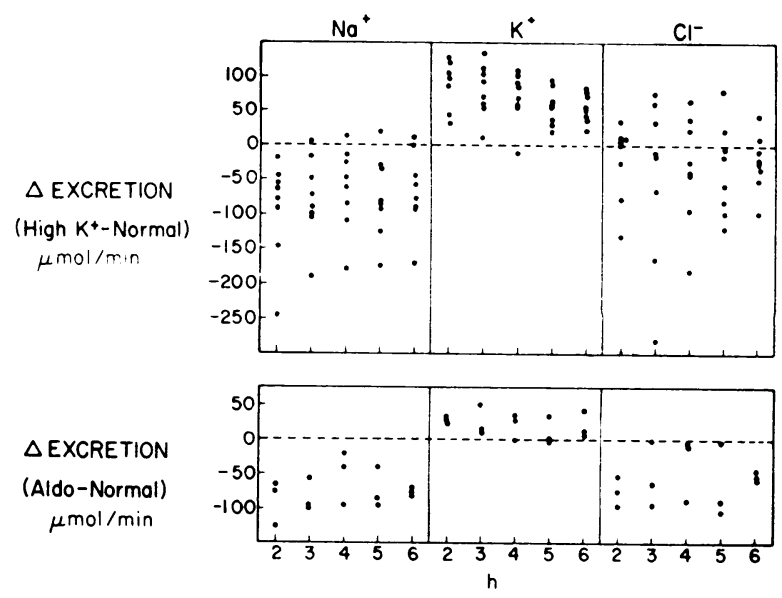

Figure 3 The effect of a high potassium diet and of aldosterone on urinary electrolyte excretion after the ingestion of $\mathrm{NH}_{4} \mathrm{Cl}$. As shown in the upper panel, a high potassium intake resulted in significantly diminished sodium and increased potassium excretion without any change in chloride excretion. Aldosterone, as shown in the lower panel, similarly resulted in diminished sodium and a more modest increase in potassium excretion; however, chloride excretion was also decreased.

and ammonium excretion were slightly but not consistently lower than base-line values. Although urine $\mathrm{pH}$ was unaltered during $\mathrm{NaCl}$ loading, net acid and ammonium excretion rates were comparable with the values during $\mathrm{KCl}$ loading.

In four studies, cumulative changes in urinary net acid excretion were assessed (utilizing the control period as a base line) during the potassium loading and recovery periods. Net acid excretion remained elevated throughout the entire potassium-loading period, and cumulative urinary acid loss for the period ranged from 32 to $105 \mathrm{mmol}$. If a loss of this quantity of hydrogen ion was reflected by changes in the extra- as well as intracellular compartments, a rise in plasma bicarbonate ranging from 4 to $12 \mathrm{mM}$ would have been expected. ${ }^{2}$ Furthermore only one of the four animals had returned to approximately zero urinary net acid balance at the end of the recovery period.

The increase in urinary chloride excretion during $\mathrm{KCl}$ loading exceeded the increase in urinary cation $\left(\mathrm{Na}^{+}+\mathrm{K}^{+}\right)$excretion, whereas no discrepancy between urinary chloride and cation excretion was found when the recovery and control periods were compared. This pattern of urinary cation and chloride excretion suggests increased stool cation losses accompanied by anions other than chloride during $\mathrm{KCl}$ loading.

As shown in Table III, there were no changes in

${ }^{2}$ Calculated assuming a bicarbonate distribution space equal to $50 \%$ of body weight and no change in extracellular fluid volume. 

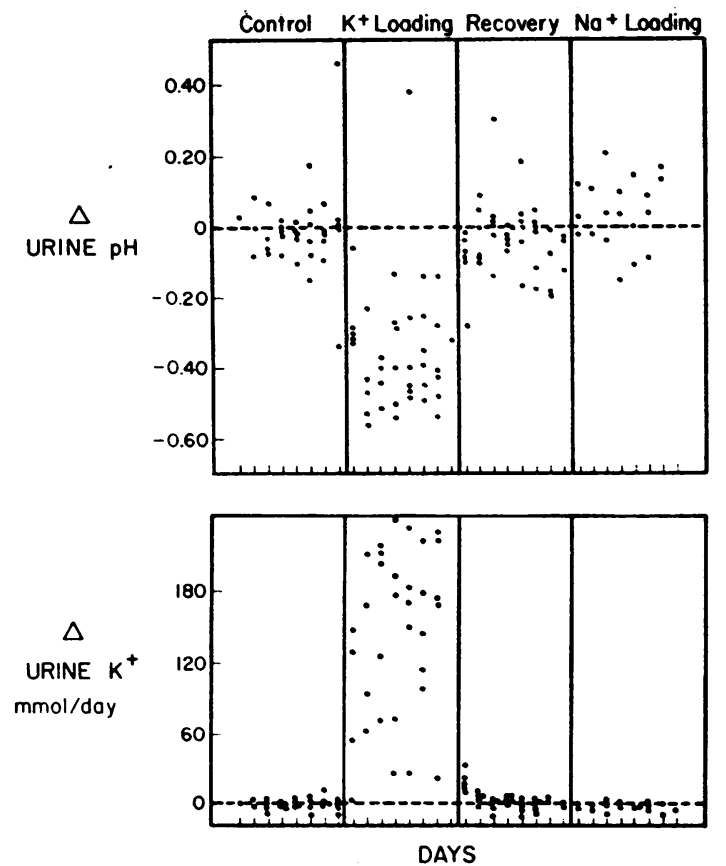

FIgUre 4 The effect of potassium and sodium intake on urine $\mathrm{pH}$ and potassium excretion in the high potassium$\mathrm{HCl}$ protocol. Potassium loading resulted in a rapid, significant, and sustained decrease in urine $\mathrm{pH}$, whereas sodium loading had no effect. Changes in urinary potassium excretion mirrored the changes in urine $\mathrm{pH}$ during potassium loading.

phosphate or organic acid excretion that would account for the decrease in urine $\mathrm{pH}$ during $\mathrm{KCl}$ loading, and the excretion rates were similar during $\mathrm{NaCl}$ loading. Urine-free ammonia concentration decreased significantly from 62 to $32 \mu \mathrm{M}$ during potassium loading, but did not change detectably during sodium loading.

Adrenalectomy protocol. In an effort to determine if the changes observed in the high potassium- $\mathrm{HCl}$ studies were a result of increased aldosterone secretion, adrenalectomized dogs on a constant maintenance dose of gluco- and mineralocorticoid were subjected to the same maneuvers.

No changes in plasma acid-base values that could be attributed to potassium or sodium loading were found; however, plasma bicarbonate concentration increased progressively but minimally throughout the study averaging $16.3 \mathrm{mM}$ in the control period, $17.7 \mathrm{mM}$ during potassium loading, $17.8 \mathrm{mM}$ during recovery, and 18.9 $\mathrm{mM}$ during sodium loading. No changes in either blood $\mathrm{pH}$ or $\mathrm{Pco}_{2}$ were evident.

As shown in Fig. 6 and Table III, urine $\mathrm{pH}$ responded to potassium loading in the same fashion as the animal with intact adrenals, decreasing from a mean of 5.91 to 5.56 during ingestion of $5 \mathrm{mmol} / \mathrm{kg}$ per day of $\mathrm{KCl}$ and returning to 5.82 during recovery. All three animals developed vomiting and/or diarrhea during potassium loading with $10 \mathrm{mmol} / \mathrm{kg}$ per day and one died. The two animals who eventually stabilized did so at a lower urine $\mathrm{pH}$ value than occurred with the 5 $\mathrm{mmol} / \mathrm{kg}$ per day level. Contrary to the studies of dogs with intact adrenal glands, the decrease in urine $\mathrm{pH}$ was not accompanied by changes in ammonium or net acid excretion, nor were any changes in phosphate or organic acid observed. In addition, an increase in the dose of mineralocorticoid to $2 \mathrm{mg}$ /day of deoxycorticosterone acetate (Doca) did not alter urine $\mathrm{pH}$ during potassium loading in the one animal tested, as shown in Fig. 6.

As in the prior protocol, no changes in urine $\mathrm{pH}$ occurred during sodium loading and there were no changes in net acid or ammonium excretion. Urine $\mathrm{NH}_{\mathbf{s}}$ responded in a fashion similar to the animals with intact adrenal glands decreasing from 67 to $23 \mu \mathrm{M}$ during potassium loading, and remaining unaltered during sodium loading. Potassium chloride was added to control urine specimens in vitro, so that final potassium concentrations (range 230-250 mM) exceeded the actual urine potassium concentration during in vivo potassium loading. This resulted in a mean decrease in urine $\mathrm{pH}$ of 0.01 (range +0.01 to -0.04 ), indicating that the decrease in urine $\mathrm{pH}$ in vivo does not result from altered urine ionic strength.

\section{Electrolyte}

Plasma potassium concentration increased during potassium loading in both the high potassium- $\mathrm{HCl}$ (3.6 to $4.0 \mathrm{mM}$ ) and adrenalectomy (3.8 to $4.6 \mathrm{mM}$ ) protocols and returned to base-line levels during the recovery period; however, it remained unaltered in the high potassium protocol ( 3.9 to $3.9 \mathrm{mM}$ ). Urinary potassium excretion during the high potassium- $\mathrm{HCl}$ protocol is shown in Fig. 4. Potassium excretion increased strikingly on the 1st day of potassium loading and decreased

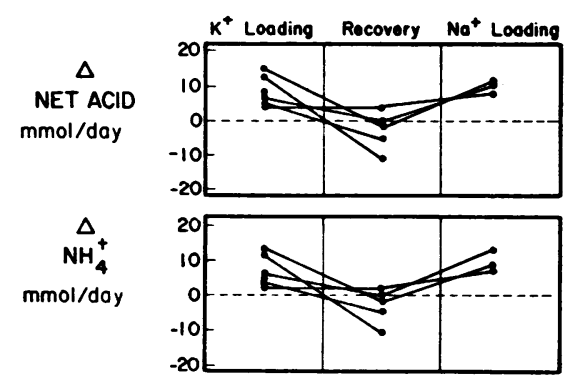

Figure 5 The effect of potassium and sodium intake on net acid and ammonium excretion in the high potassium$\mathrm{HCl}$ protocol. Potassium loading resulted in a significant increase in both net acid and ammonium excretion; however, no differences are noted when potassium- and sodiumloading periods are compared. 
TABLE III

Mean Urinary Acid-

\begin{tabular}{|c|c|c|c|c|c|c|c|c|c|}
\hline & \multirow{2}{*}{$\begin{array}{c}\text { Daily } \\
\mathrm{K}^{+} \text {intake }\end{array}$} & \multicolumn{4}{|c|}{$\mathrm{pH}$} & \multicolumn{4}{|c|}{ Net acid } \\
\hline & & Cont. & $\mathrm{K}^{+}$ & Rec. & $\mathrm{Na}+8$ & Cont. & $\mathrm{K}^{+}$ & Rec. & $\mathrm{Na}^{+}$ \\
\hline & $\mathrm{mmol} / \mathrm{kg}$ & \multicolumn{8}{|c|}{$m m o l / d a y$} \\
\hline \multicolumn{10}{|l|}{ High potassium protocol } \\
\hline $\operatorname{Dog} 1$ & 5 & 6.00 & 6.03 & & & 64.3 & 68.5 & & \\
\hline $\operatorname{Dog} 1$ & 10 & 6.00 & 6.06 & & & 64.3 & 66.5 & & \\
\hline Dog 3 & 10 & 5.74 & 5.61 & 5.84 & & 46.6 & 48.0 & 42.4 & \\
\hline $\operatorname{Dog} 4$ & 10 & 6.06 & 6.20 & 6.02 & & 53.2 & 44.5 & 44.3 & \\
\hline \multicolumn{10}{|l|}{ Paired means $\|$} \\
\hline Control vs. $\mathrm{K}^{+}$loading & & 5.95 & 5.98 & & & 57.1 & 56.9 & & \\
\hline $\mathrm{K}^{+}$loading vs. recovery & & & 5.91 & 5.93 & & & 46.3 & 43.4 & \\
\hline \multicolumn{10}{|l|}{ High potassium- $\mathrm{HCl}$ protocol } \\
\hline Dog 1 & 10 & & 5.36 & 5.66 & 5.80 & & 138.9 & 132.8 & 143.1 \\
\hline $\operatorname{Dog} 1$ & 10 & & 5.41 & & & & 169.1 & & \\
\hline $\operatorname{Dog} 2$ & 5 & 5.84 & 5.57 & 5.78 & 5.82 & 69.1 & 73.5 & 73.2 & 77.2 \\
\hline $\operatorname{Dog} 2$ & 10 & 5.84 & 5.46 & & & 69.1 & 77.5 & & \\
\hline Dog 3 & 10 & 5.73 & 5.31 & 5.72 & 5.72 & 69.8 & 84.8 & 69.1 & 79.5 \\
\hline $\operatorname{Dog} 4$ & 10) & 5.78 & 5.63 & 5.88 & & 69.2 & 82.4 & 58.2 & \\
\hline $\operatorname{Dog} 5$ & 10 & 5.81 & 5.42 & 5.78 & & 77.9 & 84.0 & 72.8 & \\
\hline Dog 6 & 10 & 5.79 & 5.35 & 5.63 & & & 89.3 & 92.1 & \\
\hline \multicolumn{10}{|l|}{ Paired means } \\
\hline Control vs. $\mathrm{K}^{+}$loading & & 5.80 & $5.46 ף$ & & & 71.0 & $80.4 \rrbracket$ & & \\
\hline $\mathrm{K}^{+}$loading vs. recovery & & & 5.44 & $5.74 \Phi$ & & & 92.2 & 83.0 & \\
\hline Control vs. recovery & & 5.79 & & 5.76 & & 71.5 & & 68.3 & \\
\hline Recovery vs. $\mathrm{Na}^{+}$loading & & & & 5.72 & $5.78 \Phi$ & & & 91.7 & 99.9 \\
\hline $\mathrm{K}^{+}$loading vs. $\mathrm{Na}^{+}$loading & & & 5.41 & & $5.78 \%$ & & 99.1 & & 99.9 \\
\hline \multicolumn{10}{|l|}{ Adrenalectomy protocol } \\
\hline Dog 2 & 5 & 5.96 & 5.60 & 5.90 & 6.08 & 62.2 & 73.2 & 58.8 & 62.3 \\
\hline $\operatorname{Dog} 2$ & 10 & 5.96 & 5.40 & & & 62.2 & 68.2 & & \\
\hline Dog 5 & 5 & 5.82 & 5.51 & 5.80 & 5.69 & 77.2 & 56.9 & 65.4 & 70.9 \\
\hline Dog 6 & 5 & 5.96 & 5.56 & 5.76 & 5.86 & 72.0 & 78.9 & 77.5 & 80.6 \\
\hline Dog 6 & 10 & 5.96 & 5.44 & & & 72.0 & 75.8 & & \\
\hline \multicolumn{10}{|l|}{ Paired means } \\
\hline Control vs. $\mathrm{K}^{+}$loading & & 5.93 & $5.50 \Upsilon$ & & & 69.1 & 70.6 & & \\
\hline $\mathrm{K}^{+}$loading vs. recovery & & & 5.56 & $5.82 ף$ & & & 69.7 & 67.2 & \\
\hline Control vs. recovery & & 5.91 & & 5.82 & & 70.5 & & 67.2 & \\
\hline Control vs. $\mathrm{Na}^{+}$loading & & 5.91 & & & 5.88 & 70.5 & & & 71.3 \\
\hline $\mathrm{K}^{+}$loading vs. $\mathrm{Na}^{+}$loading & & & 5.56 & & 5.88 & & 69.7 & & 71.3 \\
\hline
\end{tabular}

* Mean excretion rates for the entire period.

$\ddagger$ Daily intake during the potassium-loading period.

$\$$ Cont., control period; $\mathrm{K}^{+}$, potassium-loading period; Rec., recovery period; $\mathrm{Na}^{+}$, sodium-loading period.

$\|$ Mean values of all paired observations for the two periods indicated.

I Indicates difference between periods is significant $(P<0.05)$.

promptly when intake was diminished, closely paralleling the changes in urine $\mathrm{pH}$. A similar response was noted in the adrenalectomy protocol and excretion rates in adrenalectomized animals were virtually identical with those of animals wth intact adrenals ingesting comparable quantities of potassium.

\section{DISCUSSION}

In contrast to the alkalinizing effect of an acute potassium chloride infusion, chronic ingestion of a high potas- sium intake results in a diminution in urine $\mathrm{pH}$ in both normal men and dogs. As shown in Figs. 1 and 4, after an acute ammonium chloride load in humans and during daily ingestion of a small amount of hydrochloric acid in dogs, urine $\mathrm{pH}$ is lower in the potassium-loaded state. Furthermore, this effect persists in the dog studies so long as a high potassium intake is maintained. It is generally accepted that acute potassium chloride administration alkalinizes urine by diminishing distal tubular hydrogen ion secretion (1). Furthermore, it has been 
Base Parameters*

\begin{tabular}{|c|c|c|c|c|c|c|c|c|c|c|c|}
\hline \multicolumn{4}{|c|}{ Ammonium } & \multicolumn{4}{|c|}{ Phosphate } & \multicolumn{4}{|c|}{ Organic acids } \\
\hline Cont. & $\mathrm{K}^{+}$ & Rec. & $\mathrm{Na}^{+}$ & Cont. & $\mathrm{K}^{+}$ & Rec. & $\mathrm{Na}^{+}$ & Cont. & $\mathrm{K}^{+}$ & Rec. & $\mathrm{Na}^{+}$ \\
\hline \multicolumn{12}{|c|}{$m m o l / d a y$} \\
\hline 52.3 & 59.3 & & & 20.8 & 23.4 & & & & & & \\
\hline 52.3 & 59.6 & & & 20.8 & 22.7 & & & & & & \\
\hline 39.0 & 40.4 & 33.9 & & 11.7 & 11.6 & 13.8 & & & & & \\
\hline 45.3 & 41.8 & 38.2 & & 13.2 & 8.6 & 10.4 & & & & & \\
\hline \multirow[t]{4}{*}{47.2} & 50.3 & & & 16.6 & 16.6 & & & & & & \\
\hline & 41.1 & 36.1 & & & 10.1 & 12.1 & & & & & \\
\hline & 120.8 & 114.4 & 127.1 & & 24.2 & 26.2 & 23.7 & & & & \\
\hline & 149.3 & & & & 26.4 & & & & & & \\
\hline 59.0 & 61.4 & 60.9 & 66.3 & 15.5 & 16.9 & 18.1 & 16.4 & 13.8 & 14.2 & 15.3 & 13.9 \\
\hline 59.0 & 64.5 & & & 15.5 & 17.7 & & & 13.8 & 15.9 & & \\
\hline 61.3 & 74.2 & 60.7 & 69.7 & 13.3 & 14.6 & 13.3 & 15.4 & 18.0 & 18.8 & 17.2 & 18.7 \\
\hline 62.5 & 75.7 & 52.0 & & 9.7 & 10.4 & 9.7 & & 15.6 & 18.0 & 13.2 & \\
\hline \multirow[t]{2}{*}{67.3} & 70.7 & 62.0 & & 16.8 & 18.0 & 17.5 & & 20.2 & 24.0 & 16.6 & \\
\hline & 74.3 & 79.7 & & & 19.7 & 18.8 & & & & & \\
\hline \multirow[t]{2}{*}{61.8} & 69.3 ป & & & 14.2 & $15.5 \rrbracket$ & & & 16.3 & $18.2 \uparrow$ & & \\
\hline & 79.5 & 71.6 & & & 17.3 & 17.3 & & & 18.8 & 15.6 & \\
\hline \multirow[t]{3}{*}{62.5} & & 58.9 & & 13.8 & & 14.7 & & 16.9 & & 15.6 & \\
\hline & & 78.7 & 87.7 & & & 19.2 & 18.5 & & & 16.3 & 16.3 \\
\hline & 85.5 & & 87.7 & & 18.6 & & 18.5 & & 16.5 & & 16.3 \\
\hline 52.4 & 61.9 & 49.5 & 56.0 & 16.2 & 15.7 & 14.7 & 12.9 & 16.3 & 16.5 & 14.9 & \\
\hline 52.4 & 61.9 & & & 16.2 & 8.7 & & & & & & \\
\hline 65.1 & 48.5 & 57.6 & 60.4 & 17.7 & 11.7 & 12.0 & 15.4 & 21.1 & 16.4 & 12.4 & \\
\hline 66.3 & 68.8 & 67.5 & 74.0 & 10.2 & 14.8 & 15.4 & 14.7 & 16.2 & 16.8 & 16.8 & \\
\hline 66.3 & 63.4 & & & 10.2 & 17.3 & & & & & & \\
\hline \multirow[t]{2}{*}{60.5} & 60.9 & & & 14.1 & 13.6 & & & 17.9 & 16.6 & & \\
\hline & 59.7 & 58.2 & & & 14.1 & 14.0 & & & 16.6 & 14.7 & \\
\hline 61.3 & & 58.2 & & 14.7 & & 14.0 & & 17.9 & & 14.7 & \\
\hline \multirow[t]{2}{*}{61.3} & & & 63.5 & 14.7 & & & 14.3 & & & & \\
\hline & 59.7 & & 63.5 & & 14.1 & & 14.3 & & & & \\
\hline
\end{tabular}

proposed that this event may be mediated by a decrease in renal tubular cell hydrogen ion content $(2,3)$. If such a mechanism does occur acutely, it is difficult to support its persistence in the chronic setting in which an enhanced hydrogen ion gradient must be explained.

Chronic potassium loading may affect urine acidification even in the absence of an acidifying stimulus. In the human experiments, urine $\mathrm{pH}$ of the control (preammonium chloride) collections appeared to be lower in the potassium-loaded state in spite of a higher rate of urine flow. Dogs ingesting only potassium chloride showed no changes in urine $\mathrm{pH}$, but urine $\mathrm{Pco}_{2}$ increased markedly. The data do not distinguish between alternative explanations for this finding, one of which is enhanced bicarbonate reabsorption at distal tubular sites where the disequilibrium phenomenon exists $(15,16)$. Granting this possibility, an increase in urine $\mathrm{P}_{\mathrm{CO}_{2}}$ could reflect a decrease in tubular fluid $\mathrm{pH}$ at distal sites. Clearly, changes in $\mathrm{pH}$ were only defined unequivocally in response to an acidifying stimulus, and the subse- 


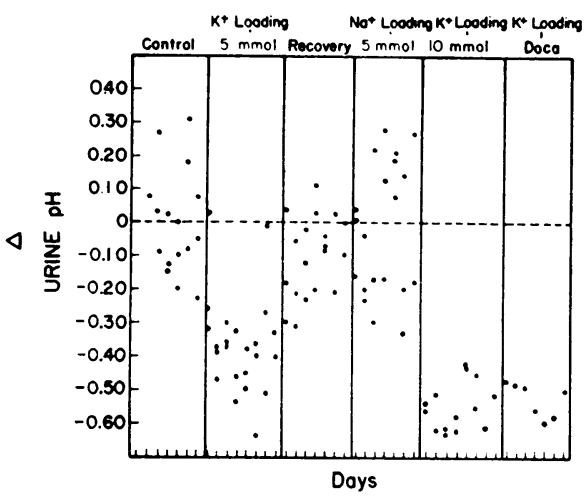

Figure 6 The effect of potassium and sodium intake on urine $\mathrm{pH}$ in the adrenalectomy protocol. Potassium loading with both $5 \mathrm{mmol} / \mathrm{kg}$ and $10 \mathrm{mmol} / \mathrm{kg}$ decreased urine $\mathrm{pH}$ and the changes appeared larger with the higher intake. An increase in the dose of Doca during potassium loading did not alter urine $\mathrm{pH}$ and urine $\mathrm{pH}$ was unaffected by sodium loading.

quent discussion addresses this aspect of the studies. Nevertheless, it should be emphasized that similar phenomenon may be operative in the absence of an acid load.

In neither the animal nor human studies could the decrease in urine $\mathrm{pH}$ be explained by changes in plasma acid-base status; urinary fixed-buffer excretion, i.e. phosphate, creatinine or organic acids; rate of urine flow or urinary ionic strength $(17,18)$. Furthermore the decrease is not the result of an increase in net acid excretion. In the human studies when mean rates of net acid excretion were compared, there was no difference between the potassium-loaded and normal state. In addition, when changes in urine $\mathrm{pH}$ were related to changes in net acid excretion, as shown in Fig. 2, the largest decreases in urine $\mathrm{pH}$ were accompanied by decreases in net acid excretion.

The changes in net acid excretion in the animal studies were potentially confusing and require more detailed analysis. The decrease in urine $\mathrm{pH}$ during potassium chloride loading was accompanied by an increase in net acid excretion when compared with collections during the control period. Although plasma bicarbonate concentration did not increase progressively, daily net acid excretion remained elevated throughout the entire potassium-loading period; and cumulative urinary net acid loss greatly exceeded that expected for the small rise in plasma bicarbonate concentration. This increased acid excretion could reflect an acid deficit that was disproportionately distributed to the intracellular space. Alternatively, it might not indicate a change in body hydrogen ion balance, but rather be due to increased acid production or increased stool bicarbonate or bicarbonate precursor losses (19). The lack of equivalent suppres- sion of acid excretion during the recovery period in three of four studies, as well as the pattern of urinary chloride and cation losses, favors the latter alternatives.

In spite of no change in urine $\mathrm{pH}$, net acid excretion during sodium chloride loading was comparable with that found during potassium chloride loading. This suggests that the change in net acid excretion is a nonspecific effect of increasing the cation and chloride content of the diet, while the decrease in urine $\mathrm{pH}$ is an independent event specifically related to potassium intake. Thus it would appear that changes resulting from manipulation of dietary potassium can be assessed most appropriately by comparing the potassium and sodium chloride-loading periods, in which case the only alteration made was in the character of the cation. Furthermore in the adrenalectomy protocol, net acid excretion remained unaltered during both potassium and sodium chloride loading, whereas urine $\mathrm{pH}$ decreased in response to the high potassium intake. Therefore, the decrease in urine $\mathrm{pH}$ in the animal, as in the human studies, does not seem to be the result of an increase in net acid excretion.

As well as decreasing urine $\mathrm{pH}$, potassium loading appears to alter ammonia metabolism. In the human studies mean rates of ammonium excretion were slightly, but not significantly, lower in the potassium-loaded state. On the other hand, when changes in urine $\mathrm{pH}$ were related to changes in ammonium excretion, as shown in Fig. 2, the largest decrements in urine $\mathrm{pH}$ were associated with decreases in ammonium excretion. Admittedly the decrease in ammonium, as well as in net acid excretion was quantitatively small and difficult to identify. These changes are impressive, however, because an increase rather than a decrease in both parameters might be expected to accompany a decrease in urine $\mathrm{pH}$. A concomitant decrease in urine $\mathrm{pH}$, ammonium excretion, and net acid excretion is indicative of a primary decrease in ammonia diffusion into the urine.

Further support for reduced ammonia diffusion into the urine is provided by the simultaneous decrease in urine $\mathrm{pH}$ and daily ammonium excretion recently documented in the potassium-loaded rat $^{3}(20)$. Either a decrease in renal ammonia production or an increase in renal blood flow can decrease the amount of ammonia available for diffusion into the urine. Since renal ammonia production was unchanged with in vitro study of renal cortical slices from potassium-loaded rats (20),

\footnotetext{
3 Although an increase rather than decrease in urine $\mathrm{pH}$ in rats chronically adapted to potassium was described in another recent study, the measurements were apparently made after anesthesia and preparation of the animals for micropuncture and were not accompanied by net acid data (3).
} 
and measurements of renal blood flow during potassium adaptation have not been reported; a definitive conclusion must await further study. Although the renal slice data mitigate against a decrease in renal ammonia production, it is still a tempting speculation in view of the well-documented increase in renal ammonia production that accompanies potassium depletion (4, 21-26).

On the other hand, the dog studies, in which ammonium excretion was unchanged when potassium and sodium-loading periods were compared and during the adrenalectomy protocol, suggest that a decrease in ammonia diffusion alone is inadequate to explain the decrease in urine $\mathrm{pH}$ during potassium loading. Although a decrease in ammonia availability could be reflected by unchanged ammonium excretion in the presence of a lower urine $\mathrm{pH}$, an additional mechanism concomitantly stimulating hydrogen ion excretion would be required to explain the lack of a concurrent diminution in net acid excretion as well as why urine $\mathrm{pH}$ decreased.

Alterations in electrolyte metabolism during potassium adaptation and their possible relationship to changes in urine acidification merit consideration. Ingestion of a high potassium diet in humans resulted in an initial natriuresis that coincided with the period of potassium retention $(13,27-29)$. The concomitant chloruresis, negative water balance, and weight loss suggest that contraction of the extracellular space occurred simultaneously, supporting the conclusion from animal studies (30-32) that potassium can affect sodium reabsorption independent of volume control. Recent micropuncture studies in rats suggest that this initial natriuresis may result from a decrease in sodium reabsorption at proximal tubular sites $(3,32)$.

On the other hand, after the ingestion of $\mathrm{NH}_{4} \mathrm{Cl}$, comparison of the high potassium with normal studies revealed diminished sodium excretion with increased potassium excretion, no difference in chloride excretion, and an increase in calculated $\left(\mathrm{Cl}^{-}-\mathrm{Na}^{+}\right)$excretion. This constellation of findings is most consistent with an increase in sodium reabsorption at distal tubular sites in exchange for an increase in potassium excretion and complements the finding by micropuncture techniques that sodium reabsorption by the distal tubule is enhanced in rats chronically ingesting a high potassium diet (3). Furthermore the exact opposite sequence of events apparently obtains in potassium depletion during which proximal sodium reabsorption appears to be enhanced (33-35) and distal reabsorption diminished (4) with a concurrent decrease in aldosterone secretion (13). These data raise the possibility that a readjustment in sites of sodium reabsorption and changes in aldosterone secretion serve as regulatory devices for maintaining simultaneous sodium and potassium homeostasis during alterations in potassium intake.
Several events related to renal electrolyte handling could theoretically influence urinary acidification. Since aldosterone secretion is increased during potassium loading $(13,14)$, it could be responsible for the decrease in urine $\mathrm{pH}$. Studies in humans testing the effect of exogenous aldosterone administration on the response to ammonium chloride resulted in no detectable change in urine $\mathrm{pH}$. Furthermore urine $\mathrm{pH}$ decreased during potassium loading in adrenalectomized dogs receiving a constant dose of maintenance steroid replacement, providing unequivocal evidence that this phenomenon is not mediated by alterations in adrenal secretion.

Since potassium loading apparently increases distal sodium delivery, its effects on urinary acidification could be related in some manner to this phenomenon. The lack of change in urine $\mathrm{pH}$ during sodium loading in both dogs with intact adrenals and adrenalectomized animals mitigates against this possibility and indicates, as well, that the decrease in urine $\mathrm{pH}$ is not a nonspecific effect of either cation or anion loading. Finally, the increased potential difference across the distal tubule, demonstrated recently in the potassium adapted rat (3), would favor increased tubular fluid hydrogen ion concentration providing all other conditions were the same. However, since this segment of the tubule is in diffusion equilibrium for ammonia with the remainder of the renal cortex $(36,37)$, an increase in ammonia trapping and hence ammonium and net acid excretion would be expected concomitantly if this mechanism alone were responsible for the decrease in urine $\mathrm{pH}$.

Since an increase in aldosterone secretion, distal tubular sodium reabsorption and potential difference would all favor hydrogen ion loss, a decrease in ammonia availability might serve to counteract these stimuli and maintain hydrogen ion homeostasis. Furthermore it might also serve a role in the maintenance of potassium homeostasis, enhancing potassium excretion by impeding hydrogen ion secretion in exchange for reabsorbed sodium. A similar speculation has been entertained previously in regard to the relationship between increased ammonia produced and potassium conservation (4). It only implies that ammonia availability might modulate the relationship between the excretory rates of potassium and hydrogen ion, but not that it would control their absolute excretory rates that are subject to multiple influences. The persistence of the urinary $\mathrm{pH}$ change and its virtual parallel with changes in potassium excretion during potassium loading in animals strengthen the possibility that the changes in urine acidification might reflect a homeostatic mechanism. This close link between hydrogen ion and potassium regulation during potassium adaptation, as well 
as the role of ammonia metabolism, require further exploration.

\section{ACKNOWLEDGMENTS}

The invaluable early contributions to this project by Dr. Richard Donn merit recognition as well as the surgical assistance of Dr. Roger Foster, and the efforts of Mrs. B. Lovejoy and Mrs. J. Pastore in preparation of the manuscript.

The low electrolyte food powder $7000 \mathrm{~J}$ used in these studies was kindly supplied by Mead Johnson Labs., Evansville, Ind.; the $d$-aldosterone acetate in sesame oil by Ciba Pharmaceutical Co., Summit, N. J.; the hydrocortisone by Merck Sharp \& Dohme, West Point, Pa.; the deoxycorticosterone acetate by Organon Inc., West Orange, N. J.; the Solu-Medrol by The Upjohn Co., Kalamazoo, Mich.; and the Florinef Acetate by E. R. Squibb \& Sons, Princeton, N. J.

This study was supported by U. S. Public Health Service Grant RO1-AM 14225 and U. S. Public Health Service Clinical Research Center Grant RR-109. Dr. Wedell was supported by Training Grant 5 TO1 AM 05086-15.

\section{REFERENCES}

1. Berliner, R. W. 1959-60. Renal mechanisms for potassium excretion. Harrey Lect. 55 : 141.

2. Berliner, R. W. 1971. Outline of renal physiology. In Diseases of the Kidney. M. B. Strauss and L. G. Welt, editors. Little, Brown and Co., Boston. 2nd edition. $1: 65$.

3. Wright, F. S., N. Strieder, N. B. Fowler, and G. Giebisch. 1971. Potassium secretion by distal tubule after potassium adaptation. Am. J. Physiol. 221: 437.

4. Tannen, R. L. 1970. The effect of uncomplicated potassium depletion on urine acidification. J. Clin. Invest. 49: 813.

5. Berliner, R. W., T. J. Kennedy, Jr., and J. G. Hilton. 1950. Renal mechanisms for excretion of potassium. Am. J. Physiol. 162 : 348.

6. Alexander, E. A., and N. G. Levinsky. 1968. An extrarenal mechanism of potassium adaptation. J. Clin. Invest. $47: 740$.

7. Schultze, R. G., D. D. Taggart, H. Shapiro, J. P. Pennell, S. Caglar, and N. S. Bricker. 1971. On the adaptation in potassium excretion associated with nephron reduction in the dog. J. Clin. Invest. 50: 1061.

8. Polak, A., G. D. Hayne, R. M. Hays, and W. B. Schwartz. 1961. Effects of chronic hypercapnia on electrolyte and acid-base equilibrium. I. Adaptation. $J$. Clin. Invest. $40: 1223$.

9. Fiske, C. H., and Y. Subbarow. 1925. The colorimetric determination of phosphorus. J. Biol. Chem. 66: 375 .

10. McCullough, H. 1967. The determination of ammonia in whole blood by a direct colorimetric method. Clin. Chim. Acta. $17: 297$.

11. Henry, R. J. 1967. Clinical Chemistry, Principles and Techniques. Harper \& Row, Publishers, New York. 292.

12. Van Slyke, D. D., and W. W. Palmer. 1920. Studies of acidosis. XVI. The titration of organic acids in urine. J. Biol. Chem. $41: 567$.

13. Brunner, H. R., L. Baer, J. E. Sealey, J. G. G. Ledingham, and J. H. Laragh. 1970. The influence of potassium administration and of potassium deprivation on plasma renin in normal and hypertensive subjects. J. Clin. Invest. $49: 2128$.

14. Williams, G. H., R. G. Dluhy, and R. H. Underwood. 1970. The relationship of dietary potassium intake to the aldosterone stimulating properties of ACTH. Clin. Sci. (Oxf.). 39: 489.

15. Rector, F. C., Jr., N. W. Carter, and D. W. Seldin. 1965. The mechanism of bicarbonate reabsorption in the proximal and distal tubules of the kidney. J. Clin. Invest. $44: 278$.

16. Vieira, F. L., and G. Malnic. 1968. Hydrogen ion secretion by rat renal cortical tubules as studied by an antimony microelectrode. Am. J. Physiol. 214: 710.

17. Tannen, R. L. 1969. The relationship between urine $\mathrm{pH}$ and acid excretion-the influence of urine flow rate. $J$. Lab. Clin. Med. $74: 757$.

18. Woeber, K. A., E. L. Reid, I. Kiem, and A. G. Hills. 1963. Diffusion of gases out of the distal nephron segment in man. I. $\mathrm{NH}_{3}$. J. Clin. Invest. 42: 1689.

19. Lennon, E. J., J. Lemann, Jr., and J. R. Litzow. 1966. The effects of diet and stool composition on the net external acid balance of normal subjects. J. Clin. Invest. $45: 1601$.

20. Kamm, D. E. 1971. Dissociation of urine $\mathrm{pH}$ and $\mathrm{NH}_{3}$ excretion during $\mathrm{KCl}$ and $\mathrm{NaCl}$ loading. Abstracts of the American Society of Nephrology. 5: 36.

21. Iacobellis, M., E. Muntwyler, and G. E. Griffin. 1954. Enzyme concentration changes in the kidneys of protein- and/or potassium-deficient rats. Am. J. Physiol. $178: 477$.

22. Goldstein, L. 1964. Relation of renal glutamine transaminase- $\omega$-amidase activity to ammonia excretion in the rat. Nature (Lond.). 201: 1229.

23. Goodman, A. D., R. E. Fuisz, and G. F. Cahill, Jr. 1966. Renal gluconeogenesis in acidosis, alkalosis and potassium deficiency: its possible role in regulation of renal ammonia production. J. Clin. Invest. 45: 612.

24. Pagliara, A. S., and A. D. Goodman. 1970. Relation of renal cortical gluconeogenesis, glutamate content and production of ammonia. J. Clin. Invest. 49: 1967.

25. Gabuzda, G. J., and P. W. Hall, III. 1966. Relation of potassium depletion to renal ammonium metabolism and hepatic coma. Medicine (Baltimore). 45: 481.

26. Baertl, J. M., S. M. Sancetta, and G. J. Gabuzda. 1963. Relation of acute potassium depletion to renal ammonium metabolism in patients with cirrhosis. J. Clin. Invest. $42: 696$.

27. Loeb, R. F., D. W. Atchley, D. W. Richards, Jr., E. M. Benedict, and M. E. Driscoll. 1932. On the mechanism of nephrotic edema. J. Clin. Invest. 11: 621.

28. Gamble, J. L. 1953. Early history of fluid replacement therapy. Pediatrics. $11: 554$.

29. Keith, N. M., and M. W. Binger. 1935. Diuretic action of potassium salts. J. Am. Med. Assoc. 105: 1584

30. Vander, A. J. 1970. Direct effects of potassium on renin secretion and renal function. Am. J. Physiol. 219: 455.

31. Sealey, J. E., I. Clark, M. B. Bull, and J. H. Laragh. 1970. Potassium balance and the control of renin secretion. J. Clin. Invest. 49: 2119.

32. Brandis, M., J. Keyes, and E. E. Windhager. 1972. Potassium-induced inhibition of proximal tubular fluid reabsorption in rats. Am. J. Physiol. 222: 421.

33. Lennon, E. J., and J. Lemann, Jr. 1968. The effect of a potassium-deficient diet on the pattern of recovery from experimental metabolic acidosis. Clin. Sci. (Oxf.). $34: 365$. 
34. Bank, N., and H. S. Aynedjian. 1964. A micropuncture study of the renal concentrating defect of potassium depletion. Am. J. Physiol. 206: 1347.

35. Jones, N. F., M. Mylle, and C. W. Gottschalk. 1965. Renal tubular microinjection studies in normal and potassium-depleted rats. Clin. Sci. (Oxf.). 29: 261.
36. Denis, G., H. Preuss, and R. Pitts. 1964. The $\mathrm{PNH}_{\mathrm{s}}$ of renal tubular cells. J. Clin. Invest. 43 : 571.

37. Oelert, H., E. Uhlich, and A. G. Hills. 1968. Messungen des ammoniakdruckes in den corticalen tubuli der rattenniere. Pfluegers Arch. Gesamte Physiol. Menschen Tiere. $300: 35$. 